\title{
Analisis Penentuan Prioritas Platform Media Sosial pada Performa Pemasaran UKM: Kasus di Kota Surabaya
}

\author{
Faras Pramesti, Berto Mulia Wibawa, dan Puti Sinansari \\ Departemen Manajemen Bisnis, Institut Teknologi Sepuluh Nopember (ITS) \\ e-mail: berto@mb.its.ac.id
}

\begin{abstract}
Abstrak-Perkembangan teknologi informasi saat ini berdampak pada peningkatan pemanfaatan media sosial yang dapat mempermudah segala aktivitas. Pengguna media sosial terbesar di Indonesia didominasi oleh usia kerja produktif, salah satunya pelaku usaha kecil menengah (UKM). Peralihan UKM yang bersifat konvensional menjadi digital melalui media sosial dapat meningkatkan pertumbuhan ekonomi di Indonesia, namun di Kota Surabaya jumlah pelaku UKM yang memanfaatkan medua sosial tergolong rendah. Penelitian ini bertujuan untuk menentukan urutan prioritas platform media sosial yang paling berpengaruh pada performa pemasaran UKM di Kota Surabaya. Teknik pengumpulan data dengan menggunakan kuesioner perbandingan berpasangan analytic hierarchy process (AHP) pada 9 pelaku UKM di Kota Surabaya dari 4 subsektor berbeda yang telah memanfaatkan media sosial selama minimal 2 tahun. Hasil penelitian ini menunjukkan jika platform media sosial yang paling berpengaruh pada performa pemasaran UKM di Kota Surabaya adalah platform Instagram, kemudian secara berurutan platform Facebook, website atau blog, dan YouTube.
\end{abstract}

Kata Kunci-Analytic Hierarchy Process (AHP),

\section{PENDAHULUAN}

$\mathrm{K}$ EBERADAAN media sosial telah lama hadir, namun hingga saat ini perannya tetap mendominasi di masyarakat dikarenakan inovasi yang terus berjalan. Survei menyatakan hingga Januari 2019 total pengguna aktif media sosial jumlahnya sebesar 150 juta jiwa atau sebesar 56 persen dari total populasi penduduk Indonesia dengan urutan pengguna paling aktif, diantaranya YouTube, WhatsApp, Facebook, dan Instagram [1]. Pengguna aktif media sosial tersebut didominasi oleh dewasa berusia 25 tahun hingga 34 tahun [2]. Hal tersebut berarti pengguna aktif media sosial di Indonesia didominasi oleh usia kerja produktif baik dari kalangan karyawan maupun pelaku usaha sebagai media pemasaran, salah satunya UKM.

Berdasarkan hasil survei Dinas Koperasi dan Usaha Mikro, Kecil, dan Menengah hingga tahun 2018 jumlah UMKM di Kota Surabaya mencapai 260.762 usaha yang terbagi menjadi 8 sektor [3]. Namun, hingga tahun 2016 angka pemanfaatan media sosial oleh UMKM binaan Dinas Perdagangan Kota Surabaya hanya sebesar 15 persen dari total UMKM binaan [4]. Persentase tersebut relatif rendah jika dibandingkan dengan total keseluruhan UKM yang terdapat di Kota Surabaya. Rendahnya persentase tersebut disebabkan karena kurangnya pengetahuan pelaku UKM dalam memanfaatkan teknologi [5]. Selain itu, alasan lainnya adalah pelaku UKM ingin menjaga urusan pribadinya dengan tidak membagikan informasi melalui media sosial dan hadirnya berita yang bersifat hoax serta pemalsuan membuat pelaku UKM menghindari pemanfaatan media sosial bagi usahanya.

Penelitian terdahulu menjelaskan bahwa pemanfaatan Facebook sebagai platform media sosial paling tepat digunakan pada performa bisnis UKM diikuti oleh platform Instagram, Twitter, Facebook, dan YouTube. Hal tersebut dikarenakan platform tersebut dapat meningkatkan kesadaran merek, menciptakan hubungan yang lebih baik dengan pelangan, dan adanya peningkatan penjualan [6]. Pemanfaatan plaform media sosial Facebook dan Twitter dalam UKM juga memiliki manfaat kinerja yang lebih baik dalam meningkatkan kinerja pemasaran [7]. Selain itu, penelitian terdahulu mengenai UKM di Kota Surabaya juga telah dilakukan oleh Rahmadita et al. (2018) [8] yang membahas tentang UKM sektor jasa.

Berdasarkan penjelasan tersebut, penelitian ini penting dilakukan untuk menentukan urutan prioritas platform media sosial yang paling berpnengaruh pada performa pemasaran UKM di Kota Surabaya. Sehingga, penelitian ini dapat memberikan rekomendasi platform media sosial yang efektif dalam meningkatkan performa pemasaran baik kepada UKM di Kota Surabaya yang belum memanfaatkan media sosial sebagai media pemasaran maupun telah memanfaatkan media sosial.

\section{LANDASAN TEORI}

\section{A. Pemasaran Pada Usaha Kecil Menengah (UKM)}

Pemasaran dapat.didefinisikan sebagai suatu proses menciptakan, berkomunikasi, memberikam, dan bertukar penawaran yang memiliki nilai bagi pelanggan, klien, mitra, serta masyarakat umum [9]. Sedangkan, pemasaran pada usaha kecil menengah (UKM) dikaitkan dengan hubungan perilaku kewirausahaan [10].

Pemasaran pada UKM dapa dilakukan melalui 2 metode yaitu metode konvensional atau offline marketing dan metode digital atau online marketing.Perbedaan antara pemasaran dengan metode konvensional dan metode digital tersebut yaitu pada biaya pemasaran yang berkaitan dengan kualitas dan jangkauan target, waktu, dan media pemasaran yang digunakan[11].

\section{B. Media Sosial}

Media sosial disebut juga media yang dihasilkan konsumen dan didefinisikan sebagai aplikasi berbasis internet dengan konten yang dihasilkan oleh konsumen, biasanya terkait dengan 
pengalaman dan konten yang dibagikan secara online untuk memudahkan akses kepada orang lain [12]. Beberapa kelebihan dari pemanfaatan media sosial diantaranya sebagai sarana berbagi ide, alat komunikasi, sumber informasi, alat pemasaran, alat interaksi pelanggan, dan hemat biaya [13]-[15].

Revolusi digital dan media sosial telah mengubah cara organisasi menarik dan mempertahankan calon konsumen [16]. Konsumen memanfaatkan media sosial untuk mencari informasi dan ulasan karena dianggap sebagai informasi yang dapat dipercaya daripada media tradisional dan membuat beberapa organisasi beralih dari iklan televisi, radio, serta majalah ke media sosial [17]. Platform media sosial berdasarkan pengguna aktif terbanyak di dunia diantaranya Facebook, YouTube, WhatsApp, Facebook Messenger, Wechat, dan Instagram [1].

\section{Usaha Kecil Menengah}

Usaha kecil menengah (UKM) memiliki peran penting dalam sektor bisnis masa kini [18]. Usaha kecil memiliki jumlah tenaga kerja sebesar 5 sampai dengan 19 orang, sedangkan usaha menengah memiliki jumlah tenaga kerja sebesar 20 sampai dengan 99 orang [19]. Kemudian usaha kecil memiliki jumlah kekayaan bersih lebih dari Rp50.000.000,00 sampai dengan Rp500.000.000,00 per tahun tanpa tanah dan bangunan usaha dengan hasil penjualan tahunan lebih dari Rp300.000.00,00 sampai dengan Rp2.500.000.000,00. Selain itu, usaha menengah memiliki jumlah kekayaan bersih lebih dari Rp500.000.000,00 sampai degan Rp10.000.000.000 per tahun tanpa tanah dan bangunan usaha dengan hasil penjualan tahunan mencapai lebih dari Rp2.500.000.000,00 sampai dengan Rp50.000.000.000,00 [20].

\section{Performa Pemasaran}

Performa pemasaran merupakan keefektivan dan efisiensi kegiatan pemasaran perusahaan terkait dengan tujuan pasar, seperti pendapatan, pertumbuhan, dan pangsa pasar [21]. Pemanfaatan media sosial berkontribusi pada peningkatan performa bisnis pada aspek pemasaran UKM [6]. Berikut ini merupakan penjelasan dari beberapa performa bisnis pada aspek pemasaran, diantaranya:

\section{1) Meningkatkan konsumen setia}

Peningkatakan pemanfaatan media sosial pada suatu usaha mengarah pada peningkatkan konsumen dan prospek pencarian bisnis pada website [22]. UKM yang menggunakan platform media sosial seperti blog atau website untuk berbagi informasi seputar produk dapat membuat konsumen selalu melakukan pembelian produk. Konsumen juga menyebarkan informasi yang didapatkan kepada orang lain melalui media sosial. Menurut pelaku usaha, bisnisnya dapat berjalan lancar dengan konsumen baru dan konsumen loyal akibat adanya hubungan secara online.

\section{2) Meningkatkan kesadaran merek, loyalitas merek, dan} reputasi merek

Semakin banyak konsumen yang menyadari adanya UKM melalui platform media sosial, maka semakin kuat reputas UKM tersebut. Dampaknya terjadi peningkatan pada potensi keuntungan dan nilai merk suatu usaha. Hal tersebut menyebabkan konsumen menjadi lebih loyal karena citra merek yang kuat. Adanya komunikasi yang era tantara pelaku usaha dengan konsumen melalui media sosial membuat sumber informasi dalam UKM menjadi terpercaya. Sehingga terciptanya kesadaran merek dan loyalitas merek [23].

3) Mengurangi komunikasi dan biaya pemasaran

Sebelum memanfaatkan media sosial, UKM memiliki keterbatasan dalam mengakses konsumen melalui metode tradisional terkait faktor biaya pemasaran. Keuntungan yang dimiliki apabila UKM menggunakan media sosial dibandingkan media offline adalah mengurangi biaya dalam pemasangan iklan dan poster [24]-[26].

\section{4) Meningkatkan pendapatan}

Pemanfaatan media sosial mampu menciptakan nilai yang membuat pendapatan lebih tinggi melalui iklan online dan sponsor. UKM yang menggunakan memanfaatkan media sosial dapat memberikan penawaran ekslusif bagi followers mereka berdasarkan tingkat pelanggan dan frekuensi pembelian. Adanya penawaran eksklusif dan diskon pembelian membuat UKM dapat mendorong konsumen untuk melakukan pembelian berulang. Selain itu, media sosial dapat membantu UKM untuk mengarahkan konsumen setia mengeluarkan lebih banyak uang dalam setiap pembelian [27].

\section{5) Menarik konsumen baru}

UKM dapat menarik konsumen baru melalui media sosial dengan membuat konten yang disesuaikan dengan kebutuhan konsumen potensial sehingga meningkatkan tujuan dan target UKM tersebut [28], [29]. Hal tersebut menyebabkan fenomena baru yang dikenal sebagai penularan sosial atau peristiwa yang terjadi ketika adopsi merupakan fungsi dari paparan pengetahuan, sikap, atau perilaku orang lain [30]. Semakin banyak followers, like, comment, dan sharing yang terjadi pada media sosial maka semakin banyak arahan yang dihasilkan terhadap UKM.

6) Meningkatkan daya saing

UKM dapat mencari data melalui media sosial untuk menganalisis dan menemukan wawasan baru, seperti merek dan tren yang populer. Hal tersebut membuat UKM mampu memahami hal yang dilakukan oleh kompetitor dan cara perubahan suatu industri. Hasil temuan tersebut dapat diartikan jika penggunaan media sosial dapat mencapai keunggulan kompetitif terhadap kompetitor mereka [31]. Selain itu, pengalaman positif konsumen melalui media sosial dapat mendorongnya untuk merekomendasikan merek dan produk UKM tersebut kepada orang lain.

\section{METODE PENELITIAN}

\section{A. Desain Penelitian}

Jenis desain penelitian yang digunakan dalam penelitian ini adalah exploratory - direct dengan pendekatan kualitatif yang merupakan suatu metode riset yang tidak terstruktur dan sifatnya menjelaskan suatu hal yang mengacu pada sampel kecil serta dapat memberikan wawasan mengenai masalah yang terjadi [32]. Data yang dibutuhkan merupakan data primer pada 9 pelaku UKM di Kota Surabaya yang telah memanfaatkan media sosial minimal 2 tahun diantaranya platform Facebook, Instagram, YouTube, dan website atau blog. 
Tabel 1.

UKM Terpilih di Kota Surabaya

\begin{tabular}{lcc}
\hline \hline Nama UKM & Subsektor & Tahun memanfaatkan media sosial \\
\hline UKM A & Kuliner & 10 tahun \\
UKM B & Desain Produk & 6 tahun \\
UKM C & Kuliner & 13 tahun \\
UKM D & Kuliner & 5 tahun \\
UKM E & Kuliner & 5 tahun \\
UKM F & Fashion & 6 tahun \\
UKM G & Kuliner & 4 tahun \\
UKM H & Kuliner & 2 tahun \\
UKM I & Fotografi & 3 tahun \\
\hline \hline
\end{tabular}

\section{B. Sampel UKM Terpilih}

Terdapat beberapa langkah dalam menentukan sampel UKM terpilih di Kota Surabaya. Langkah pertama dimulai dengan melakukan pencarian UKM di Kota Surabaya yang memanfaatkan media sosial sebagai media pemasaran dan ditemukan sejumlah 92 UKM, kemudian langkah kedua dilakukan klasifikasi UKM pada masing-masing subsektor diantaranya kuliner, fashion, desain produk, dan fotografi. Kriteria pemilihan UKM yaitu telah memanfaatkan platform media sosial berupa Facebook, Instagram, website atau blog, dan YouTube dengan minimal pemanfaatan selama 2 tahun.

Hasil pemilihan UKM berdasarkan kriteria tersebut hanya sejumlah 15 UKM yang memenuhi kriteria. Langkah terakhir dalam memilih sampel UKM yaitu dengan melakukan perizinan kepada tiap pelaku UKM, namun hanya didapatkan sejumlah 9 UKM di Kota Surabaya yang bersedia memberikan data mengenai usahanya seperti yang tertera pada Tabel 1 .

\section{Perancangan Data}

Penelitian ini menggunakan kuesioner perbandingan berpasangan analytic hierarchy process (AHP) untuk menentukan urutan prioritas platform media sosial yang paling berpengaruh pada performa pemasaran UKM di Kota Surabaya. Kuesioner perbandingan AHP disebar kepada 9 responden dalam pengambilan keputusan untuk peringkat kepentingan [33]. Selanjutnya, isi kuesioner diurutkan berdasarkan kriteria dan alternatif keputusan model hierarki AHP. Rancangan kuesioner perbandingan AHP terdiri dari beberapa bagian, diantaranya:

\section{1) Pendahuluan}

Bagian ini berisi latar belakang penelitian, tujuan penelitian, dan contact person yang dapat dihubungi oleh responden jika terdapat pertanyaan saat melakukan pengisian kuesioner.

\section{2) Model hierarki $A H P$}

Pada bagian model hierarki AHP terdiri dari beberapa level. Tujuan berada pada level teratas yaitu menentukan urutan prioritas platform media sosial yang paling berpengaruh pada performa pemasaran UKM di Kota Surabaya, dilanjutkan 8 kriteria pada aspek pemasaran diantaranya konsumen setia; kesadaran merek, loyalitas, dan reputasi merek; biaya pemasaran; pendapatan; konsumen baru; daya saing; kepercayaan konsumen; jangkauan pasar dan informasi. Level paling bawah model hierarki yaitu alternatif keputusan berupa platform Facebook, Instagram, YouTube, dan website.

3) Petunjuk Pengisian Kuesioner

Bagian petunjuk pengisian kuesioner dapat membantu
Tabel 2.

Penjelasan Skala Perbandingan Berpasangan Kuesioner

\begin{tabular}{cl}
\hline \hline Angka & \multicolumn{1}{c}{ Definisi } \\
\hline 1 & Kedua indikator sama pentingnya \\
3 & $\begin{array}{l}\text { Indikator (A) sedikit lebih penting dibandingkan indikator } \\
\text { (B) }\end{array}$ \\
5 & Indikator (A) lebih penting dibandingkan indikator (B) \\
7 & Indikator (A) sangat lebih penting dibandingkan indikator \\
& (B) \\
9 & Indikator (A) mutlak lebih penting dibandingkan indikator \\
& (B) \\
$2,4,6,8$ & Nilai kompromi diantara dua nilai keputusan terdekat
\end{tabular}

memudahkan responden dalam pengisian kuesioner menggunakan skala penilaian perbandingan berpasangan pada kuesioner yang terdapat pada Tabel 2.

4) Daftar Pertanyaan

Pada bagian daftar pertanyaan ini terdapat penilaian perbandingan berpasangan pada setiap tingkat model hierarki AHP dalam bentuk tabel perbandingan relatif berpasangan untuk menghitung kriteria agar dapat menentukan alternatif keputusan yaitu urutan prioritas platform media sosial yang paling berpengaruh pada performa pemasaran.

\section{Analisis Data}

Analisis data dilakukan setelah melakukan penyebaran dan pengisian kuesioner perbandingan berpasangan kepada responden dengan menggunakan metode analisis AHP. Metode tersebut membagi permasalahan pengambilan keputusan multicriteria menjadi minimum 3 tingkatan yaitu goal atau tujuan, kriteria, dan alternatif keputusan. Penelitian ini menggunakan aplikasi "Expert Choice 11.1" dengan beberapa tahap analisis, diantaranya:

\section{1) Mendefinisikan dan dekomposisi tujuan ke level lebih rendah}

Pada tahap ini tujuan dilakukan metode analytic hierarchy process (AHP) dijelaskan secara rinci dan dilakukan dekomposisi atau membagi tujuan menjadi level yang lebih rendah kemudian digunakan dalam menyusun struktur model hierarki permasalahan [34].

\section{2) Pengembangan model hierarki AHP}

Pada tahap ini perumusan struktur model hierarki AHP dilakukan yang meliputi tujuan, kriteria dari delapan aspek pemasaran, dan alternatif keputusan yang merupakan platform media sosial yang digunakan dalam media pemasaran UKM, yaitu Facebook, Instagram, YouTube, dan website atau blog.

\section{3) Pengumpulan data dan pairwise comparison}

Tahap pengumpulan data pada penelitian ini dilakukan dengan metode penilaian oleh 9 pelaku UKM di Kota Surabaya melalui penyebaran kuesioner perbandingan AHP. Terdapat 3 langkah yang dilakukan dalam tahap pairwise comparison [35]. Langkah pertama adalah konstruksi matriks pairwise comparison, kemudian dilakukan perhitungan prioritas atau bobot relatif kombinasi, dan terakhir perhitungan bobot lokal untuk kriteria utama dan alternatif keputusan.

4) Menghitung rasio konsistensi dari pairwise comparison

Perhitungan tingkat konsistensi penilaian yang dilakukan oleh responden dalam metode AHP menggunakan metode consistency ratio $(\mathrm{CR})$ dengan kisaran nilai antara 0,0 ( 0 persen 
Tabel 3. Hasil Pembobotan Kriteria dan Alternatif Keputusan

\begin{tabular}{|c|c|c|c|c|}
\hline Kriteria & $\begin{array}{l}\text { Alternatif } \\
\text { Keputusan }\end{array}$ & $\begin{array}{l}\text { Bobot } \\
\text { Kriteria }\end{array}$ & $\begin{array}{l}\text { Bobot } \\
\text { Lokal } \\
\text { Alternatif } \\
\text { Keputusan }\end{array}$ & $\begin{array}{l}\text { Bobot } \\
\text { Global } \\
\text { Alternatif } \\
\text { Keputusan }\end{array}$ \\
\hline $\begin{array}{l}\text { Konsumen } \\
\text { setia }\end{array}$ & $\begin{array}{l}\text { Facebook } \\
\text { Instagram } \\
\text { YouTube } \\
\text { Website/blog }\end{array}$ & 0,107 & $\begin{array}{l}0,234 \\
0,537 \\
0,076 \\
0,154\end{array}$ & $\begin{array}{l}0,046 \\
0,107 \\
0,015 \\
0,031\end{array}$ \\
\hline $\begin{array}{l}\text { Kesadaran } \\
\text { merek, } \\
\text { loyalitas } \\
\text { merek, dan } \\
\text { reputasi } \\
\text { merek }\end{array}$ & $\begin{array}{l}\text { Facebook } \\
\text { Instagram } \\
\text { YouTube } \\
\text { Website/blog }\end{array}$ & 0,090 & $\begin{array}{l}0,197 \\
0,558 \\
0,112 \\
0,132\end{array}$ & $\begin{array}{c}0,032 \\
0,09 \\
0,018 \\
0,021\end{array}$ \\
\hline $\begin{array}{l}\text { Biaya } \\
\text { pemasaran }\end{array}$ & $\begin{array}{l}\text { Facebook } \\
\text { Instagram } \\
\text { YouTube } \\
\text { Website/blog }\end{array}$ & 0,038 & $\begin{array}{c}0,27 \\
0,502 \\
0,086 \\
0,141\end{array}$ & $\begin{array}{c}0,02 \\
0,038 \\
0,007 \\
0,011\end{array}$ \\
\hline Pendapatan & $\begin{array}{l}\text { Facebook } \\
\text { Instagram } \\
\text { YouTube } \\
\text { Website/blog }\end{array}$ & 0,207 & $\begin{array}{l}0,187 \\
0,568 \\
0,072 \\
0,173\end{array}$ & $\begin{array}{l}0,068 \\
0,207 \\
0,026 \\
0,063\end{array}$ \\
\hline $\begin{array}{l}\text { Konsumen } \\
\text { baru }\end{array}$ & $\begin{array}{l}\text { Facebook } \\
\text { Instagram } \\
\text { YouTube } \\
\text { Website/blog }\end{array}$ & 0,136 & $\begin{array}{l}0,163 \\
0,553 \\
0,074 \\
0,209\end{array}$ & $\begin{array}{c}0,04 \\
0,136 \\
0,018 \\
0,052\end{array}$ \\
\hline Daya saing & $\begin{array}{l}\text { Facebook } \\
\text { Instagram } \\
\text { YouTube } \\
\text { Websiteblog }\end{array}$ & 0,049 & $\begin{array}{l}0,159 \\
0,466 \\
0,228 \\
0,148 \\
0,206\end{array}$ & $\begin{array}{l}0,017 \\
0,049 \\
0,024 \\
0,016\end{array}$ \\
\hline $\begin{array}{l}\text { Kepercayaan } \\
\text { konsumen }\end{array}$ & $\begin{array}{l}\text { Facebook } \\
\text { Instagram } \\
\text { YouTube } \\
\text { Website/blog }\end{array}$ & 0,248 & $\begin{array}{l}0,206 \\
0,526 \\
0,089 \\
0,179\end{array}$ & $\begin{array}{l}0,097 \\
0,248 \\
0,042 \\
0,084\end{array}$ \\
\hline $\begin{array}{l}\text { Jangkauan } \\
\text { pasar dan } \\
\text { informasi }\end{array}$ & $\begin{array}{l}\text { Facebook } \\
\text { Instagram } \\
\text { YouTube } \\
\text { Website/blog }\end{array}$ & 0,125 & $\begin{array}{l}0,181 \\
0,532 \\
0,066 \\
0,221\end{array}$ & $\begin{array}{l}0,042 \\
0,125 \\
0,015 \\
0,052\end{array}$ \\
\hline
\end{tabular}

inconsistency) sampai dengan 1,0 (100 persen inconsistency). Nilai rasio konsistensi yang dapat diterima adalah kurang dari sama dengan nol, apabila nilai rasio setelah pembobotan lebih dari nilai yang telah ditentukan maka hasilnya tidak konsisten.

\section{ANALISIS DAN DISKUSI}

\section{A. Pengumpulan Data}

Pengumpulan data pada penelitian ini dilakukan dengan cara menyebarkan kuesioner perbandingan AHP pada bulan Desember 2019, dimana peneliti datang secara langsung kepada 9 pelaku UKM untuk memberikan dan mendampingi pengisian kuesioner. Kemudian pengisian kuesioner perbandingan AHP dilakukan dengan durasi antara 30 menit sampai dengan 45 menit bergantung pada wawasan dan pemahaman tiap pelaku UKM.

\section{B. Hasil Pembobotan Hierarki AHP}

Hasil pembobotan hierarki AHP didapatkan setelah dilakukannya input nilai dari seluruh responden ahli yang merupakan 9 pelaku UKM di Kota Surabaya melalui aplikasi "Expert Choice 11.1". Pembobotan kombinasi kriteria dan alternatif keputusan yang telah mengalami perhitungan dapat
Tabel 4.

Tingkat Rasio Konsistensi Kombinasi

\begin{tabular}{lcc}
\hline \hline Kriteria & $\begin{array}{l}\text { Rasio Konsistensi } \\
\text { Tiap Kriteria }\end{array}$ & $\begin{array}{l}\text { Rasio Konsistensi } \\
\text { Keseluruhan }\end{array}$ \\
\hline $\begin{array}{l}\text { Konsumen setia } \\
\text { Kesadaran merek, }\end{array}$ & 0,01 & \\
loyalitas merek, reputasi & 0,01 & \\
merek & 0,01 & \\
$\begin{array}{l}\text { Biaya pemasaran } \\
\text { Pendapatan }\end{array}$ & 0,02 & 0,01 \\
$\begin{array}{l}\text { Konsumen baru } \\
\text { Daya saing }\end{array}$ & 0,01 & \\
Kepercayaan konsumen & 0,02 & \\
Jangakauan pasar dan & 0,00 & \\
informasi & 0,02 & \\
\hline \hline
\end{tabular}

Tabel 5.

Prioritas Kriteria Dampak Pemanfaatan Media Sosial Pada UKM

\begin{tabular}{clc}
\hline \hline $\begin{array}{c}\text { Peringkat } \\
\text { Prioritas }\end{array}$ & \multicolumn{1}{c}{ Kriteria } & Bobot \\
\hline 1 & Kepercayaan Konsumen & 0,248 \\
2 & Pendapatan & 0,207 \\
3 & Konsumen baru & 0,136 \\
4 & Jangkauan pasar dan informasi & 0,125 \\
5 & Konsumen setia & 0,107 \\
6 & Kesadaran merek, loyalitas merek, & 0,09 \\
& dan reputasi merek & 0,049 \\
7 & Daya saing & 0,038 \\
8 & Biaya pemasaran \\
\hline \hline
\end{tabular}

ditemukan pada Tabel 3. Hasil pembobotan tersebut terdiri dari bobot kriteria, bobot lokal alternatif keputusan, dan bobot global alternatif keputusan.

Hasil uji konsistensi pada tingkat rasio konsistensi kombinasi menunjukkan bahwa keseluruhan rasio konsistensi baik total maupun tiap kriteria adalah kurang dari 0,1 seperti pada Tabel 4. Hal ini menunjukkan bahwa hasil pembobotan yang dilakukan terhadap kriteria dan alternatif keputusan untuk menentukan urutan prioritas platform media sosial yang paling berpengaruh pada performa pemasaran UKM di Kota Surabaya dapat diandalkan.

\section{Analisis Prioritas Kriteria}

Berdasarkan hasil pembobotan kombinasi yang telah dilakukan diatas, dapat diketahui peringkat prioritas dari masing-masing kriteria berdasarkan dampak pemanfaatan media sosial pada UKM di Kota Surabaya untuk menentukan pengambilan keputusan dalam memilih media sosial yang paling berpengaruh pada performa pemasaran seperti pada Tabel 5.

\section{Analisis Prioritas Alternatif Keputusan}

Pada Tabel.6 berikut ini ditampilkan prioritas alternatif keputusan platform media sosial yang paling berpengaruh pada performa pemasaran UKM di Kota Surabaya berdasarkan tujuan hierarki. Tingkat hierarki konsistensi adalah 0,01 dimana nilai tersebut menunjukkan bahwa alternatif keputusan telah konsisten dan dapat diandalkan.

Hasil prioritas platform media sosial yang paling berpengaruh pada performa pemasaran UKM di Kota Surabaya. Prioritas pertama yaitu platform Instagram dengan bobot 0,539. Hal tersebut dikarenakan dalam meningkatkan konsumen setia 
Tabel 6.

Prioritas Alternatif Keputusan Platform Media Sosial UKM

\begin{tabular}{clc}
\hline \hline Peringkat Prioritas & Alternatif Keputusan & Bobot \\
\hline 1 & Instagram & 0,539 \\
2 & Facebook & 0,195 \\
3 & Website/Blog & 0,177 \\
4 & YouTube & 0,088 \\
\hline \hline
\end{tabular}

pelaku UKM seringkali melakukan pemberian hadiah kepada pelanggan melalui platform tersebut atau dikenal dengan sebutan give away. Meningkatkan kesadaran merek, loyalitas merek, dan reputasi merek melallui tampilan konten yang unik serta menarik perhatian konsumen. Mengurangi biaya pemasaran karena tidak adanya pengeluaran beban dalam mendaftar akun tersebut untuk pemasaran usaha, meningkatkan pendapatan melalui promosi yang dilakukan oleh endorser atau influencer, menambah jumlah konsumen baru melalui penggunaan hashtag pada setiap konten foto atau video, meningkatkan daya saing karena masih sedikitnya jumlah UKM di Kota Surabaya yang memanfaatkan platform media sosial Instagram, meningktkan kepercayaan konsumen melalui update konten secar berkala dan mengikuti balik atau melalukan follow back akun Instagram milik konsumen, dan memperluas jangkauan pasar serta informasi karena dapat menyasar konsumen tanpa adanya keterbatasan jarak mengingkat media sosial bersifat digital

Kemudian prioritas kedua yaitu platform Facebook dengan bobot global 0,195. Hal tersebut dikarenakan para pelaku UKM tersebut menghubungkan akun Instagram dengan Facebook yang dapat mempermudah koneksi dalam mengunggah foto serta informasi produk. Selain itu, platform media sosial Instagram dan Facebook merupakan media yang saling terintegrasi.

Prioritas ketiga yaitu platform website atau blog dengan bobot global 0,177. Pemanfaatan website atau blog dalam suatu usaha tentunya dapat meningkatkan kesadaran merek, loyalitas merek, dan reputasi merek UKM melalui pencarian konsumen baik yang disengaja atau tidak disengaja melalui search engine seperti Google yang juga berdampak pada peningkatan konsumen baru, konsumen setia, serta perluasan jangkauan pasar. Kemudian website atau blog dapat dibuat dan diakses secara gratis yang tentunya akan mengurangi biaya pemasaran serta secara langsung berdampak pada peningkatan pendapatan pelaku UKM.. Selain itu, pemanfaatan platform website atau blog dapat meningkatkan daya saing UKM tersebut dikarenakan minimnya jumlah pelaku UKM di Kota Surabaya yang telah memanfaatkan media tersebut dan berdampak peningkatan kepercayaan konsumen melalui pemanfaatan website secara efektif.

Prioritas keempat yaitu platform YouTube dengan bobot global 0,088. Pemanfaatan konten pemasaran melalui platform media sosial YouTube memang belum maksimal seperti ketiga platform media sosial lainnya. Namun, para pelaku UKM tersebut mengaku telah merasakan dampak dari pemanfaatan media sosial YouTube diantaranya tampilan video yang menarik dapat meningkatkan kesadaran konsumen, loyalitas, dan reputasi terhadap UKM yang juga berpengaruh pada peningkatan konsumen setia dan datangnya konsumen baru.
Selain itu, branding produk atau usaha melalui video YouTube dapat meningkatkan kepercayaan konsumen mengenai kondisi UKM sesungguhnya dan berdampak pada unggilnya UKM tersebut dibandingkan UKM konvensional.

Hal tersebut dapat diartikan jika platform Instagram dan Facebook memiliki dampak yang besar dalam membantu pemasaran UKM di Kota Surabaya. Selain itu, dikarenakan konsumen khususnya di Kota Surabaya lebih banyak yang memanfaatkan platform Instagram dan Facebook sebagai media pemasaran serta pencarian produk.

\section{KESIMPULAN DAN SARAN}

\section{A. Kesimpulan}

Berdasarkan hasil analisis AHP telah ditemukan hasil prioritas kriteria dampak pemanfaatan media sosial pada performa pemasaran. Peringkat teratas yaitu kriteria meningkatkan kepercayaan konsumen, peringkat kedua yaitu kriteria meningkatkan pendapatan, peringkat ketiga merupakan kriteria menarik konsumen baru; kemudian secara berurutan yaitu kriteria jangkauan luas dan penyebaran informasi cepat; kriteria meningkatkan konsumen setia; kriteria meningkatkan kesadaran merek, loyalitas merek, dan reputasi merek; kriteria meningkatkan daya saing, dan kriteria mengurangi komunikasi dan biaya pemasaran. Sedangkan, hasil prioritas alternatif keputusan berupa urutan platform media sosial yang paling berpengaruh pada performa pemasaran UKM di Kota Surabaya yaitu platform Instagram yang menduduki peringkat peringkat, kemudian secara berurutan yaitu Facebook, website atau blog, dan YouTube.

\section{B. Keterbatasan dan Saran Penelitian}

Terdapat beberapa keterbatasan pada penelitian ini. Pertama, pengumpulan data yang telah dilakukan hanya bersumber pada 1 orang informan selaku pemilik usaha setiap UKM dengan metode kualitatif penyebaran kuesioner perbandingan AHP. Sehingga, rentan bias pada metode yang digunakan. Kedua, pengambilan data dalam penelitian ini dilakukan pada waktu yang terbatas yaitu bulan Desember 2019, sehingga jawaban dari responden menggambar kondisi UKM sampai dengan bulan tersebut. Ketiga, responden dalam penelitian ini dianggap memiliki kemampuan pemanfaatan media sosial yang sebanding. Namun, pada kenyataannya terdapat perbedaan pengalaman kerja dan tahun pemanfaatan media sosial yang mungkin berdampak pada wawasan tiap pelaku UKM

Saran untuk penelitian selanjutnya, peneliti menyarankan untuk menggunakan metode kuantitatif untuk menghindari bias dari data yang telah diperoleh. Selain itu, dapat dilakukan penambah lokasi UKM yang bukan hanya berfokus di lingkup Kota Surabaya melainkan di Provinsi Jawa Timur.

\section{REFERENSI}

[1] S. Kemp, "Digital 2019: Indonesia," Data Reportal, Jan-2019. .

[2] Asosiasi Penyelenggara Jasa Internet Indonesia, "Buletin APJII," Asosiasi Penyelenggara Jasa Internet Indonesia, pp. 1-7, 2016.

[3] Dinas Koperasi dan UKM Provinsi Jawa Timur, "Data UMKM Se 2016 dan SUTAS 2018 PLUS TK," 2016.

[4] M. A. Himawan and I. Baihaqi, "Perancangan Social Media Marketing 
bagi Dinas Perdagangan dan Perindustrian dalam Mempromosikan Usaha Mikro Kecil dan Menengah di Kota Surabaya," J. Tek. ITS, vol. 5, no. 2, 2016.

[5] J. Braojos-Gomez, J. Benitez-Amado, and F. Javier Llorens-Montes, "How do small firms learn to develop a social media competence?," Int. J. Inf. Manage., vol. 35, no. 4, pp. 443-458, 2015.

[6] S. Z. Ahmad, N. Ahmad, and A. R. Abu Bakar, "Reflections of entrepreneurs of small and medium-sized enterprises concerning the adoption of social media and its impact on performance outcomes: Evidence from the UAE," Telemat. Informatics, vol. 35, no. 1, pp. 6-17, 2018.

[7] R. Odoom, T. Anning-Dorson, and G. Acheampong, "Antecedents of social media usage and performance benefits in small- and medium-sized enterprises (SMEs)," J. Enterp. Inf. Manag., vol. 30, no. 3, pp. 383-399, 2017.

[8] N. A. Rahmadita, B. M. Wibawa, and M. S. Hakim, "Identifikasi Permasalahan Pemanfaatan Data sebagai Dasar Pengambilan Keputusan Bisnis pada UMKM Sektor Jasa: Kasus di Surabaya," J. Sains dan Seni ITS, vol. 7, no. 1, pp. 21-25, Mar. 2018.

[9] American Marketing Association, "Definitions of Marketing," American Marketing Association, 2017.

[10] P. Lewis Reynolds, "The Need for a New Paradigm for Small Business Marketing? What is Wrong with the Old One?," J. Res. Mark. Entrep., vol. 4, no. 3, pp. 191-205, 2002.

[11] B. Ahmed and S. T. Husain, "E-Marketing: A paradigm shift in the 21st century," 2014), Redefining Manag. Pract. Mark. Mod. age, Atharva Publ., 2014.

[12] Z. Xiang and U. Gretzel, "Role of social media in online travel information search,” Tour. Manag., vol. 31, no. 2, pp. 179-188, 2010.

[13] T. D. Baruah, "Effectiveness of Social Media as a tool of communication and its potential for technology enabled connections: A micro-level study," Int. J. Sci. Res. Publ., vol. 2, no. 5, pp. 1-10, 2012.

[14] Q. L. Sutino and D. O. Siahaan, "Feature extraction from app reviews in google play store by considering infrequent feature and app description," in Journal of Physics: Conference Series, 2019, vol. 1230, no. 1.

[15] A. Puspaningrum, D. Siahaan, and C. Fatichah, "Mobile app review labeling using lda similarity and term frequency-inverse cluster frequency (TF-ICF)," in Proceedings of 2018 10th International Conference on Information Technology and Electrical Engineering: Smart Technology for Better Society, ICITEE 2018, 2018, pp. 365-370.

[16] X. Y. Leung, B. Bai, and K. A. Stahura, "The Marketing Effectiveness of Social Media in the Hotel Industry: A Comparison of Facebook and Twitter," J. Hosp. Tour. Res., vol. 39, no. 2, pp. 147-169, 2015.

[17] W. G. Mangold and D. J. Faulds, "Social media: The new hybrid element of the promotion mix," Bus. Horiz., vol. 52, no. 4, pp. 357-365, 2009

[18] L. Han, X. Xiang, and X. Yang, "Emerging economies and financing of SMEs," igi-global.com, pp. 1-24, 2018.

[19] Badan Kebijakan and P. P. R. Fiskal, "Kebijakan Antisipasi Krisis Tahun 2012 Melalui Program Kredit Usaha Rakyat (KUR)," 2012.

[20] Pemerintahan Republik Indonesia, "Undang-Undang Republik
Indonesia Nomor 20 Tahun 2008 Tentang Usaha Mikro, Kecil, dan Menengah," 2008.

[21] C. Homburg, M. Grozdanovic, and M. Klarmann, "Responsiveness to customers and competitors: The role of affective and cognitive organizational systems," J. Mark., vol. 71, no. 3, pp. 18-38, 2007.

[22] B. Schivinski and D. Dabrowski, "The effect of social media communication on consumer perceptions of brands," J. Mark. Commun., vol. 22, no. 2, pp. 189-214, 2016.

[23] R. Agnihotri, R. Dingus, M. Y. Hu, and M. T. Krush, "Social media: Influencing customer satisfaction in B2B sales," Ind. Mark. Manag., vol. 53, pp. 172-180, 2016.

[24] P. Velazques, "How Social Media Helps to Lower the Cost of Marketing - DreamGrow," dreamgrow.com, Feb-2017.

[25] E. Triandini, A. Djunaidy, and D. Siahaan, "A maturity model for ecommerce adoption by small and medium enterprises in Indonesia," $J$. Electron. Commer. Organ., vol. 15, no. 1, 2017.

[26] E. Triandini, A. Djunaidy, and D. Siahaan, "Development of a conceptual model of E-commerce adoption for SMEs in Indonesia," in Information Technology and Electrical Engineering (ICITEE), 2013, pp. 93-96.

[27] J. L. Munger and D. Grewal, "The effects of alternative price promotional methods on consumers' product evaluations and purchase intentions," $J$. Prod. Brand Manag., vol. 10, no. 3, pp. 185-197, Jun. 2001.

[28] E. Triandini, A. Djunaidy, and D. Siahaan, "Mapping requirements into e-commerce adoption level: A case study Indonesia SMEs," in 2017 5th International Conference on Cyber and IT Service Management, CITSM 2017, 2017.

[29] E. Triandini, A. Djunaidy, and D. Siahaan, "Determining e-commerce adoption level by SMEs in Indonesia based on customer-oriented benefits," in 2014 1st International Conference on Information Technology, Computer, and Electrical Engineering: Green Technology and Its Applications for a Better Future, ICITACEE 2014 - Proceedings, 2015, pp. 281-285.

[30] C. Van den Bulte, "Opportunities and Challenges in Studying Customer Networks," Connect. Cust. Chang. Nat. Consum. Bus. Mark., pp. 7-35, 2010.

[31] L. Dey, S. M. Haque, A. Khurdiya, and G. Shroff, "Acquiring competitive intelligence from social media," ACM Int. Conf. Proceeding Ser., 2011.

[32] N. Malhotra, Riset Pemasaran: Pendekatan Terapan edisi Bahasa Indonesia. PT Indeks, 2009.

[33] H. P. Ta, "A study of bank selection decisions in Singapore using the Analytical Hierarchy Process," Int. J. Bank Mark., pp. 170-180, 1991.

[34] Praveen Goyal Zillur Rahman Absar Ahmad Kazmi, "Identification and prioritization of corporate sustainability practices using analytical hierarchy process | Journal of Modelling in Management | Vol 10, No 1," Identif. prioritization Corp. Sustain. Pract. using Anal. hierarchy Process Praveen Goyal Zillur Rahman Absar Ahmad Kazmi, vol. 10, no. 1, p. , 2015.

[35] K. P. Gupta, P. Bhaskar, and S. Singh, "Prioritization of factors influencing employee adoption of e-government using the analytic hierarchy process," J. Syst. Inf. Technol., vol. 19, no. 1-2, pp. 116-137, 2017. 